\title{
Embedding Information Security Literacy in College Education
}

\author{
Jin Wang \\ School of Computer Science and Technology \\ Nantong, Jiangsu 226019, P. R. China \\ e-mail: wj@ntu.edu.cn
}

\author{
Hui Zhou \\ School of Computer Science and Technology \\ Nantong, Jiangsu 226019, P. R. China \\ e-mail:632837603@qq.com
}

\begin{abstract}
Information security becomes essential since China has entered the information society. Information security literacy will be the core quality of information literacy. College students in all disciplines must have some information security literacy. However, the current university information security education is confined to the students who major in computer science, and does not cover students of other disciplines. Now other disciplines do not have specialized information security courses. The quality of college students lags behind the level of information society in China, which leads to frequent information security incidents. Therefore, how to improve the information security literacy of college students has become a problem. This paper proposed a teaching reform method of embedding information security literacy into the existing university curriculum. This method presents information security knowledge in case study and embeds it into the existing specialized courses of various disciplines without adding new courses. It is a lightweight curriculum reform method that can be carried out rapidly. The preliminary teaching reform practice showed that this embedded teaching can effectively improve the information security literacy of College students.
\end{abstract}

\section{Keywords-Information Security Literacy; Embedded Teaching; Colleage Teaching}

\section{INTRODUCTION}

In 2015, Chinese Premier Li Keqiang first proposed the plan of developing the 'Internet + ' [1] to promote the cooperation of mobile Internet, cloud computing, big data, Internet of things with modern manufacture industries and thus facilitate the healthy development of e-commerce, industrial Internet and Internet finance. This plan indicates that "Internet + " has been placed at the level of national strategy. With the deepening of the "Internet + " strategy, China will accelerate the transition from an industrial society to an information society. This means that in the next few years, most of China's traditional enterprises will be integrated with the Internet, which requires the higher education to cultivate a large number of qualified graduates with both information literacy and professional skills. In other words, students majoring in medicine, chemicals, machinery and other traditional disciplines should also cultivate information literacy to adapt to the work and social needs in an information society. Just like the industrial society attaching great importance to power security, information security [2] is also crucial to the information society. Information security literacy [3] will be the core of information literacy that has to be acquired by the students in the traditional disciplines in order to adapt to the future information society. However, the current information security education [4] in the school is still limited to computer majors, without covering other traditional subjects and there is no specific information security courses, resulting in that information quality of the college students in China seriously falls behind the development of the information society level and the information security incidents frequently occurred. Therefore, how to improve the information security literacy of college students has become an urgent problem to be solved.

Domestic and foreign literature research shows that Europe and the United States and some other western countries are stepping ahead in the information security literacy studies and trainings [5] while China has not established any relevant organization or published any common information security promotion plan [6]. There are only a few regions and organizations having launched the similar activities. The information security literacy education for college students started late in China. In the aspect of network information security, most college students lack the information security literacy, which is manifested in: low awareness of information security and less capable of resisting the corrosion; weak consciousness of information ethics and thus easy to be deceived; lack of information security knowledge and thus unable to verify the authenticity and quality of the information; lack of information security skills; colleges and universities ignoring the information security teaching [7]. Just like other security work, the key of information security lies in people. How to improve the college students' information security literacy has become an urgent and important task in the information security education work. Luo [8] built an evaluation indicator system for information security literacy, which includes information security knowledge, information security ability, information security awareness, information ethics, and information security literacy. Cai [9] proposed four first-level indexes, eight secondary-class indexes and thirty three-class indexes to construct evaluation principles, and calculates the weights of each index.

\section{PROBLEM STATEMENT}

The information security literacy of college students is the consciousness, attitude, knowledge, technology and accomplishment of protecting themselves and others in the process of carrying out network behavior through tools such as computer and new media. The cultivation of college students' information security literacy depends on both the 
self-cultivation of college students and college education, but mainly the education of colleges and universities whose responsibilities cannot be ignored. This paper studies how to embed information security education into traditional subjects in college teaching. For example, we can increase the content of "medical information security" in the course of "college student information technology basis" to cultivate their information security literacy.

It is inevitable to improve the information security of college students. The question explored in this paper is how to embed information security literacy education in the existing curriculum. The expected advantages include: on one hand, there is no need to set up new courses to facilitate a quick implementation; on the other hand, an integration with students' majors could be realized to leave a better effect. But there are also some problems: how to embed the information security literacy education in teaching and how to evaluate the information security literacy of college students.

\section{METHODS OF EMBEDDING TEACHING}

The embedding teaching mode is not a course replace another. "Course replacement mode" is to directly replace an old course with a new one, in which the normal school teaching order would be easily interrupted, so it appears to be hard to implement. To this end, this research put forward the "embedded teaching mode". This mode does not require the school to change the current teaching plan very much, but breaks down the content of information security literacy cultivation to be embedded into the teaching as cases based on the implementation progress of the current teaching plan.

The embedded teaching model should meet the following points: (1) the content of the course is designed and taught by the major teachers and information security teachers together, so that the content of information security and major courses could be deeply integrated. (2) The information security literacy should be embedded into the existing courses step by step, so that information security literacy education could be consistent and systematic. (3) Information security literacy course embedded in the major courses is also accompanied with appropriate homework and examination rather than a simple extension outside the major courses.

This research recommend the teaching method of PBL (Problem-Based Learning) [10] to be adopted in the embedded teaching. Take the teaching of medical majors as an example, teachers can collect major medical information security incidents in the history as a case to raise questions to students for discussion. Here are some case examples:

Case 1:In 2011, Beijing Peking Union Hospital registration system broke down; In 2013, 4 hospitals' registration system in Ningbo broke down with all patients waiting for a long time. Teaching questions could be designed as: What are the reasons for the breakdown of the hospital information system? Any countermeasures?

Case 2: In 2015, Anthem, the second-largest health insurance company in the U.S., announced that hackers stole over 80 million clients' personal information, which became the most serious medical information leak in the American history. Teaching questions could be designed as: In which ways patient information might be leaked? What harm will the leakage cause?

Case 3: In 2013, Zhejiang Province ruled a case, a hacker gang stole the prescription statistics from several hospitals illegal exchanged for over 7 million yuan in four years. Prescription statistics refers to a hospital's statistical information of all prescriptions, such as the most frequently used medicine. After the illegal leakage, pharmaceutical companies can specifically promote the drugs to the hospital according to the illegally obtained data, which would seriously interrupt the normal order of the medicine market. Teaching questions could be designed as: What are the possible sources of disclosure? How to prevent?

Students can be divided into several groups. Teachers use the cases to raise up questions and let students to solve these questions through discussion and literature lookup. In the process of seeking answers, major teachers continue to guide students to broaden their professional knowledge while information security teachers instruct students to clarify what information security issues they have obtained at different times. This problem-oriented teaching model, its purpose is not to solve the problem, but rather improving the learning and teamwork capability in the process of seeking answers.

Major teacher is the key to the success of embedded teaching mode. The embedded teaching mode means that the information security teachers should collaborate with other major teachers to design, implement and evaluate the curriculum. The implementation of embedded teaching involves many entities such as teaching affairs office, department, teachers, and students and so on. How to establish a coordination and balance mechanism between these independent entities is the main problem faced by the embedded teaching. Among them, the most important is the coordination of major teachers. In addition to welcome information security teachers, major teachers should participate in information security literacy training, in order to increase their own information security literacy training. And the information security teachers should establish a close interactive cooperative relationship with the major teachers. Information security teachers can send some messages about the information security literacy through social software, and introduce skills and knowledge of information security literacy.

Resource building is very important in problem-based learning. Information security teachers should organize knowledge systems related to learning tasks from scattered information. The sources of resources should be extensive, such as books, Blog, online courses, academic databases, etc. One feature of information technology is that it updates very quickly. Teachers should constantly update their knowledge system, understand the progress of new information security, in order to prepare new curriculum cases. In the problem design, the training of students' information security awareness should be emphasized.

\section{INFORMATION SECURITY LITERACY EVALUATION}

The evaluation of information security literacy needs to be based on objective and effective evaluation index system. 
This research uses AHP [11] analytic hierarchy process to design the index system of information security literacy including three first-level indicators and six second-level indicators, along with the weight of each indicator.

\section{TABLE I. INFORMATION SECURITY LITERACY INDICATORS}

\begin{tabular}{|c|c|}
\hline $\begin{array}{c}\text { First-level } \\
\text { Indicators }\end{array}$ & $\begin{array}{c}\text { Second-level } \\
\text { Indicators }\end{array}$ \\
\hline $\begin{array}{c}\text { Information } \\
\text { security knowledge } \\
\text { (medium) }\end{array}$ & $\begin{array}{c}\text { Basic knowledge } \\
\text { Skill knowledge }\end{array}$ \\
\hline $\begin{array}{c}\text { Information } \\
\text { security awareness } \\
\text { (easy) }\end{array}$ & $\begin{array}{c}\text { Level of information security } \\
\text { understanding } \\
\text { Level of information security } \\
\text { cautiousness }\end{array}$ \\
\hline $\begin{array}{c}\text { Information } \\
\text { security capacity } \\
\text { (hard) }\end{array}$ & $\begin{array}{c}\text { Information security precaution } \\
\text { Information security processing }\end{array}$ \\
\hline
\end{tabular}

This research established a question database (Fig.1) where the test paper could be automatically generated. The paper consists of three levels of questions, simple, medium and difficult. Each level has 10 questions and the score is set to be 5 points, 3 points and 2 points according to the calculated weight ratio. After the evaluation, the evaluation system will propose different suggestions based on the proportion of question types with wrong answers. For example, if there are a lot of mistakes in the basic knowledge part, it will inform: lack of basic knowledge, please strengthen the theoretical knowledge learning.

According to the above ideas, this research implemented a real evaluation system, covering both Web (Fig.2) and Android (Fig.3).

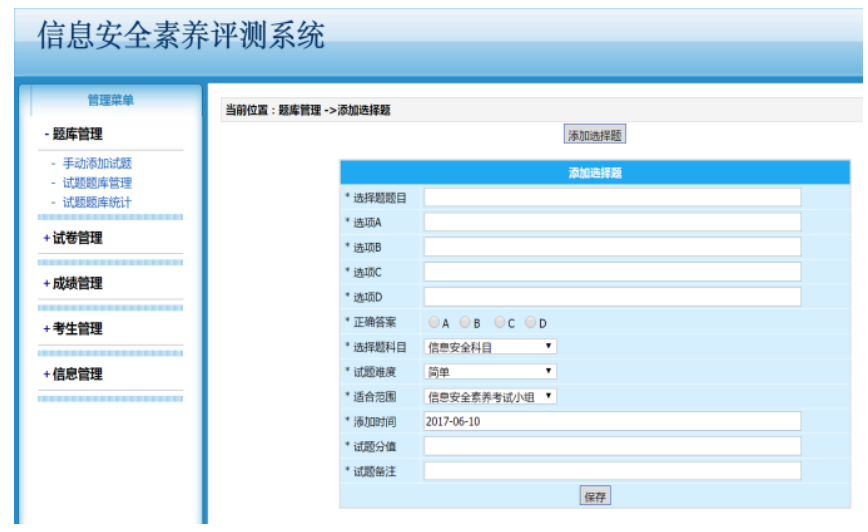

Figure 1. Information security literacy test questions management

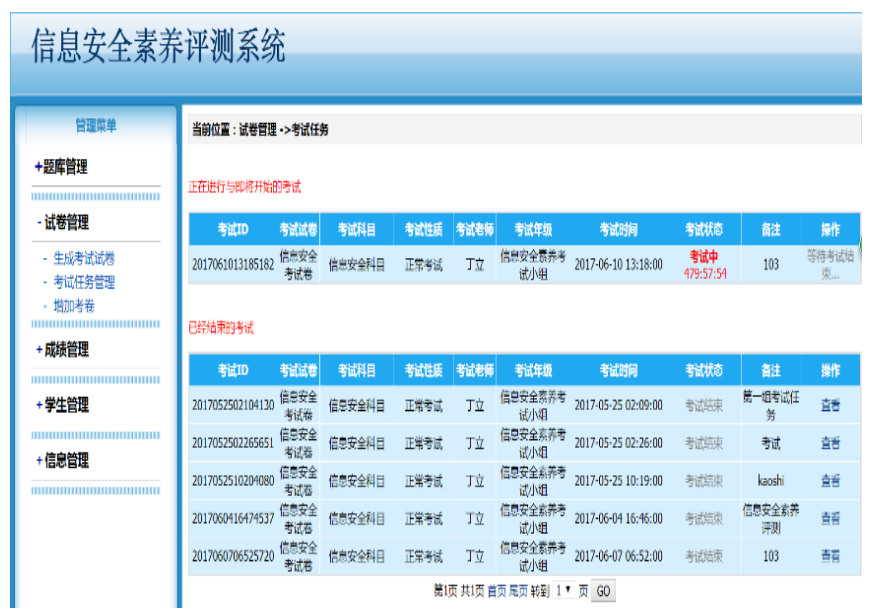

Figure 2. Information security literacy evaluation based on web

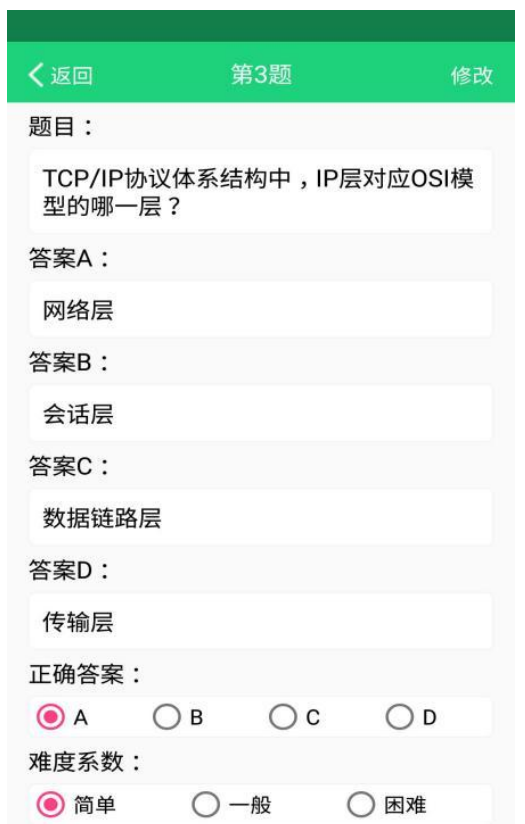

Figure 3. Information security literacy evaluation based on Android

A total of 112 students participated in the test and took the test before and after attending the updated courses, which is called the pre-test and post-test. The average score in the pre-test is 56.3. Students exposed low capability of password setting, low awareness of information security protection and weak foundation of information legal knowledge. The average score of the post-test is 81.9. After the embedded teaching of information security literacy, students cultivated a understanding of the information security issues in their majors with significantly improved information security literacy.

\section{CONCLUSIONS}

The range of information security is very large, from the national political, military, science, technology and other confidential security, to personal information and 
commercial secrets leakage. The issue of information security is not only a technical one, but also a social problem. It is a major issue that China must take serious. If it is not carefully handled, it will seriously affect the healthy development of China's informatization and may even threaten China's economic security and even national security. The lack of information security literacy will also affect the country's strategic development. China's Internet industry is running on the path at the world-leading position. In the future, with the deepening of the "Internet+" plan, China will accelerate the transition from an industrial society to an information society. This requires a group of talents with both information technology and information literacy. Embedding the information security education into the college education is of practical meaning to ensure the safe work and living in the information society, and is also consistent with the "Internet+" national strategy. As information technology has penetrated into various professions, it is difficult to set up a new information security course for each relevant major. This paper proposes to embed the information security literacy into existing professional courses. Through the joint efforts of professional teachers and information security teachers, the case teaching and PBL teaching method could be combined to improve the information security literacy of college students in multiple ways. This paper designed the evaluation index system for the information security literacy, which was applied in the teaching practice. The latest teaching evaluation shows that the embedded teaching can effectively improve the information security literacy of college students.

\section{ACKNOWLEDGMENT}

This study is supported by the Nantong University teaching reform research project (No. 2016B45).

\section{REFERENCES}

[1] Wang, Z., Chen, C., Guo, B., Yu, Z., \& Zhou, X. "Internet Plus in China." It Professional 18.3(2016):5-8.

[2] Whitman, Michael E. "In defense of the realm: understanding the threats to information security." International Journal of Information Management 24.1(2004):43-57.

[3] Ning, Y., Gao, D., Shen, X., Ye, Q., Cai, H., \& Guo, J. "Designing a Training Program for Information Security Literacy of Undergraduates Based on Ubiquitous Learning." Educational Innovation Through Technology, 2014:197-204.

[4] Rezgui, Yacine, and A. Marks. "Information security awareness in higher education: An exploratory study." Computers \& Security 27.7-8(2008):241-253.

[5] Hentea, Mariana, H. S. Dhillon, and M. Dhillon. "Towards Changes in Information Security Education. " Journal of Information Technology Education 5.5(2006):221-233.

[6] Yao, L., Zhang, Y., Zhang, W. "The current status of information security education at universities and countermeasures analysis." China Medical Education Technology (2016).

[7] Gu, Shan Shan, and Y. Shi. Research on Information Security of College Ideology. Intelligent Computing Theories and Application. Springer International Publishing, 2016.

[8] Li, Luo. "Exploreration of the Evaluation Indicator System of National Information Security Literacy." Journal of Chongqing University (2012).

[9] Cai, Hua, D. H. Gao, and L. P. Dong. "Evaluation research on information security literacy for cadets based on AHP." Information Technology (2013).

[10] Hmelosilver, Cindy E. "Problem-Based Learning: What and How Do Students Learn?." Educational Psychology Review 16.3(2004):235 266.

[11] Saaty, Thomas L. Analytic Hierarchy Process. Encyclopedia of Biostatistics. John Wiley \& Sons, Ltd, 2001:19-28. 